Please do not remove this page

RMIT

UNIVERSITY

\title{
A qualitative evaluation of breast cancer survivors' acceptance of and preferences for consumer wearable technology activity trackers
}

Nguyen, Nga; Hadgraft, Nyssa; Moore, Melissa; Rosenberg, Dori; Lynch, Christopher; Reeves, Marina; Lynch, Brigid

https://researchrepository.rmit.edu.au/esploro/outputs/9921860626101341/filesAndLinks?institution=61RMIT_INST\&index=null

Nguyen, N., Hadgraft, N., Moore, M., Rosenberg, D., Lynch, C., Reeves, M., \& Lynch, B. (2017). A qualitative evaluation of breast cancer survivors' acceptance of and preferences for consumer wearable technology activity trackers. Supportive Care in Cancer, 25(11), 3375-3384.

https://doi.org/10.1007/s00520-017-3756-y

Document Version: Accepted Manuscript

Published Version: https://doi.org/10.1007/s00520-017-3756-y

Repository homepage: https://researchrepository.rmit.edu.au

(c) Springer-Verlag Berlin Heidelberg 2017

Downloaded On 2023/04/26 10:15:58 +1000 
Thank you for downloading this document from the RMIT Research Repository.

The RMIT Research Repository is an open access database showcasing the research outputs of RMIT University researchers.

RMIT Research Repository: http://researchbank.rmit.edu.au/

\section{Citation:}

Nguyen, N, Hadgraft, N, Moore, M, Rosenberg, D, Lynch, C, Reeves, M and Lynch, B 2017, 'A qualitative evaluation of breast cancer survivors' acceptance of and preferences for consumer wearable technology activity trackers', Supportive Care in Cancer, vol. 25, no. 11, pp. 3375-3384.

See this record in the RMIT Research Repository at:

https://researchbank.rmit.edu.au/view/rmit:47994

Version: Accepted Manuscript

\section{Copyright Statement:}

(C) Springer-Verlag Berlin Heidelberg 2017

\section{Link to Published Version:}

https://dx.doi.org/10.1007/s00520-017-3756-y 


\section{A Qualitative Evaluation of Breast Cancer Survivors' Acceptance of and Preferences for Consumer}

\section{Wearable Technology Activity Trackers}

Nga H. Nguyen,1 Nyssa T. Hadgraft,2,3 Melissa M. Moore,4 Dori E. Rosenberg,5,6 Chris Lynch,7 Marina M.

Reeves,8 Brigid M. Lynch1, 2, 9

1 Cancer Epidemiology Centre, Cancer Council Victoria, Melbourne, VIC, Australia

2 Physical Activity Laboratory, Baker IDI Heart and Diabetes Institute, Melbourne, VIC, Australia

3 School of Public Health and Preventive Medicine, Monash University, Melbourne, VIC, Australia

4 Department of Medical Oncology, St Vincent's Hospital, The University of Melbourne, VIC, Australia

5 Group Health Research Institute, Seattle, USA

6 School of Public Health, The University of Washington, Seattle, USA

7 School of Health and Biomedical Sciences, RMIT University, Melbourne, VIC, Australia

8 The University of Queensland, School of Public Health, Brisbane, QLD, Australia

9 Melbourne School of Population and Global Health, The University of Melbourne, VIC, Australia

Corresponding author: Brigid M. Lynch.

Brigid.Lynch@cancervic.org.au

Telephone: +61395146209

Fax: +61395146800 


\begin{abstract}
Background: Physical inactivity and sedentary behaviour are common among breast cancer survivors. These behaviours are associated with an increased risk of comorbidities such as heart disease, diabetes and other cancers. Commercially available, wearable activity trackers (WATs) have potential utility as behavioural interventions to increase physical activity and reduce sedentary behaviour within this population.

Purpose: To explore the acceptability and usability of consumer WAT amongst postmenopausal breast cancer survivors.
\end{abstract}

Methods: Fourteen participants tested two to three randomly assigned trackers from six available models (Fitbit One, Jawbone Up 24, Garmin Vivofit 2, Garmin Vivosmart, Garmin Vivoactive and Polar A300). Participants wore each device for two weeks, followed by a one week washout period before wearing the next device. Four focus groups employing a semi-structured interview guide explored user perceptions and experiences. We used a thematic analysis approach to analyse focus group transcripts.

Results: Five themes emerged from our data: (1) Trackers increased self-awareness and motivation, (2) Breast cancer survivors' confidence and comfort with wearable technology, (3) Preferred and disliked features of WAT, (4) Concerns related to the disease and (5) Peer support and doctor monitoring were possible strategies for WAT application.

Conclusions: WATs are perceived as useful and acceptable interventions by postmenopausal breast cancer survivors. Effective WAT interventions may benefit from taking advantage of the simple features of the trackers paired with other behavioural change techniques, such as specialist counselling, doctor monitoring and peer support, along with simple manual instructions.

Keywords: Cancer survivors. Breast cancer. Physical activity. Sedentary behaviour. Wearable technology. 


\section{Compliance with Ethical Standards}

Funding: This study was funded by the National Breast Cancer Foundation (ECF-15-012 to BM Lynch).

NT Hadgraft was supported by an Australian Postgraduate Award and a Baker IDI Bright Sparks top up scholarship.

C Lynch was supported by a PhD scholarship from Northern Health.

MM Reeves was supported by a National Breast Cancer Foundation Fellowship (ECF-13-09).

Conflict of Interest: The authors declare that they have no conflict of interest.

Ethical approval: All procedures performed in studies involving human participants were in accordance with the ethical standards of the Human Research Ethics Committee of Cancer Council Victoria (IER-1503) and with the 1964 Helsinki declaration and its later amendments or comparable ethical standards.

Informed consent: Informed consent was obtained from all individual participants included in the study. 


\section{Introduction}

Physical activity (PA) after breast cancer diagnosis may ameliorate some of the late-effects of treatment and comorbid chronic disease [1]. Guidelines from peak cancer control bodies, such as the American Cancer Society [2] and Cancer Council Australia [3] recommend that cancer survivors should engage in at least 150 minutes per week of moderate-to-vigorous physical activity to improve their treatment outcomes, quality of life and overall survival. For many women who have had breast cancer, achieving this goal is challenging, and many fail to meet these guidelines [4,5]. In breast cancer, evidence from randomised controlled trials support the efficacy of PA interventions in producing short-term behaviour change, but not long-term behaviour maintenance [6]. Moreover, many of these interventions utilise in-person delivery for at least some of the intervention sessions, which requires personnel and financial resources to sustain. To date, few studies amongst cancer survivors have focused on reducing sedentary behaviour (SB), which is also associated with various adverse outcomes [7]. Wearable activity trackers (WATs) have achieved mass market penetration, with one in five adult consumers in the Australia owning one of these devices [8]. WATs have potential for use in scalable behavioural interventions to promote PA, as they encourage the use of theory-based self-regulation skills known to be associated with behaviour change [9]. One significant advantage of activity trackers is the provision of automated feedback on time spent in PA/SB. This feedback can also be integrated with other interactive behaviour change tools (e.g., mobile telephone or web-based applications). Interventions incorporating WATs and focusing on PA behaviours for senior adults have exhibited promising results [10-12].

To date, several have examined the usability of consumer WATs, yet most have included only healthy, young to middle aged participants [13]. Only a few studies have examined the acceptability of activity trackers amongst older adults or those with chronic diseases. Mercer et al. (2016) [11] conducted focus groups to examine the usability and usefulness of four different activity trackers in 32 older adults diagnosed with a chronic disease (high blood pressure, diabetes, arthritis). Activity trackers were perceived as being both useful and acceptable, but it was noted that the lack of comprehensive instruction manuals and technology skills were barriers to use. The primary limitation of this study was the short period of testing time of four days which was only able to capture very initial impressions about the devices. Another study involving 95 community-dwelling older adults (>70 years old) found the device Fitbit One was easy to use, useful and acceptable at both 10 weeks and 8 months after enrolling in the study. However, the study evaluated only one popular PA monitor and 
assessed quantitatively just two main drivers of technology acceptance, namely, perceived usefulness and perceived ease-of-use [14].

Little is known about the feasibility of using WATs in cancer survivor research. Prior to initiating intervention studies, it is essential to understand enablers and barriers to adoption of such technology, some of which may be specific to different cancer survivor populations. Therefore, the aim of this qualitative study was to explore the acceptance and usability of WATs amongst postmenopausal BCS. Our objective was to identify features of consumer WATs that would facilitate behavioural interventions focussing on increasing PA and reducing SB of this population.

\section{Methods}

The research team began by scoping all WATs that were commercially available in Australia as of May 2015. As our longer-term research goal was to utilise wearable technology in a trial setting to increase physical activity and reduce sedentary behaviour, we required devices to have two basic features in order to be included in this focus group study: a step-count (pedometer) function; and a non-movement notification. Our other inclusion criteria were: having an associated app that was user friendly (assessed by reading user reviews posted on websites including www.choice.com.au, www.gizmodo.com.au, and www.cnet.com.au) and affordable (less than \$500AUD, which excluded the Apple Watch).[15,16] Based on these criteria, we selected six devices for testing: Fitbit One, Jawbone Up24, Garmin Vivofit2, Garmin Vivosmart, Garmin Vivoactive and Polar A300 (Table 1). The selected devices had a range of different features to be explored in the focus groups. For example, the Fitbit One could be clipped to clothing, whereas others were wrist-worn. The Jawbone Up 24 could automatically track sleep quality; the Garmin Vivofit 2 used a long life battery rather than needing to be charged etc.:

--- Insert Table 1 about here ---

Participants were recruited predominantly through Register 4, an online community of Australian adults interested in participating in health-related research. We also recruited participants via Breacan, an information and support service for Victorian women living with breast/gynaecological cancer. Potential participants were contacted by a researcher (CL or BML) to complete a screening questionnaire over the telephone to determine 
eligibility. Post-menopausal women, diagnosed with stage I-III breast cancer, who had completed primary Victoria, Australia, being able to speak and write fluently in English and having daily access to a handheld device or personal computer and Internet. Informed, written consent was obtained for all eligible participants. Twenty-one women indicated an interest in the study; after screening, 14 (67\%) were deemed eligible and provided consent. Participants were randomly assigned two of the six WATs to wear for a minimum of four weeks, two weeks per device. A one-week non-wear 'wash out' period took place between wearing successive trackers. Some participants wore a third device, if time permitted before their scheduled focus group. Two researchers (NHN, CL) assisted participants to initialise their tracker and install the app on their smartphone. Participants were also briefly guided on how to operate the tracker (push button or swipe), its basic features (step counts, sitting alert) and its monitor app (how to sync) and were encouraged to sync the tracker with the app daily. At the end of the trial, all participants were invited to pre-scheduled focus groups. Four focus groups were conducted between December 2015 and October 2016. Each group included three to four participants. This number of focus group sessions was deemed appropriate when saturation point of data was reached, or no further relevant information emerged [17]. Each participant was provided with a $\$ 50$ gift card for their participation at the end of their focus group. The study protocol was approved by the Human Research Ethics Committee of Cancer Council Victoria (IER-1503).

Participants self-reported their demographic background, PA level and technical skill in a questionnaire before their focus group. The focus groups were conducted by two researchers (BML and CL) experienced in the cancer and PA context. A semi-structured interview guide was developed including open-ended questions and probes. Participants were asked about four topics: (1) awareness of monitoring PA and SB; (2) usefulness of devices in changing PA/SB; (3) ease of use and comfort with technology; and (4) feasible strategies to apply technology (Table 2). Focus groups were tape-recorded and transcribed verbatim by an independent transcriptionist. Data were analysed using a qualitative, thematic analysis approach which attempted to organise the data into themes to reflect the participants' narratives and understand their own experiences without $a$ priori hypotheses [18]. Data analysis was performed by two research members [NHN and NH]. Firstly, the researchers independently created an initial codebook after reviewing and becoming familiar with the data. All segments of the transcripts that had similar underlying meaning were assigned the same code. The two researchers, then, refined the concepts of their initial codebook and combined the codes into key themes. As new themes or 
subthemes emerged, the codebook was revised and the transcripts were re-coded. Following this process, the researchers met to discuss the identified themes and subthemes, with discrepancies resolved through consensus. Key quotes were identified that were representative of the main themes and sub-themes. NVivo 14.0 (QSR International) [19] was used to code and analyse the data.

--- Insert Table 2 about here ---

\section{Results}

Participant characteristics and study tracker allocation are summarised in Table 3. Five overarching themes about the acceptance and preference of WAT among BCS were identified from the focus group data. Selected quotes for each theme are in Table 4.

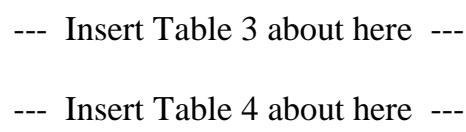

\section{Theme 1: WATs increased self-awareness and motivation of physical activity}

When asked about the usefulness of WATs, most participants reported that the trackers made them more aware of their PA/SB. Interestingly, this self-awareness increased in both active and inactive participants. However, participants tended to be aware of their active time rather than the amount of time they spent sitting. Working participants, in particular, were less likely to be aware of their sitting time, and had less supportive conditions to reduce $\mathrm{SB}$ than the non-working group.

The self-awareness of activity data collected by the trackers also acted as a prompt to encourage participants to increase their current level of PA. Participants reported feeling inspired and satisfied knowing that they achieved the targeted number of steps for a day. They also felt accountable and motivated to put in additional effort when they were close to achieving their target. This implies that a clear, achievable goal, represented by the specific number of steps, was likely the most significant motivation for participants.

Participants reported that the activity trackers helped them incorporate PA into their daily routines and increased “opportunistic" movement, e.g., park the car further away, use stairs instead of lift, etc. Nevertheless, three participants reported that they stopped using the trackers, or only used them occasionally after a period of time even though they increased their awareness and motivation to do more exercise. 
Many BCS perceived that they may have higher motivation to use WATs to increase their exercise than women without cancer, since BCS knew exercise could help prevent recurrence of cancer and improve general wellbeing. However, at the same time, treatment side effects and overall poorer health were attributed as the main barriers for BCS becoming active after cancer treatment, which in turn may imply an impediment to the WAT use to increase activity.

\section{Theme 2: Confidence and comfort with wearable technology}

12 out of 14 participants considered themselves as not "tech-savvy" or "technology skilled", yet most (11 participants) did not encounter technical difficulties in operating the basic features of the tracker and its application (smartphone or web-based). There were, however, two women who found it challenging to set up the device, get them to sync or understand how to use the app. These women also felt disinterested and demonstrated a lack of readiness to incorporate new technical platforms into their existing practices. In addition, many participants reported that they did not use all of the features of the trackers and mostly relied upon the step counts. Limited technical abilities could be one potential explanation that hindered the exploration of more advanced features, which in turn might sub-optimise the effect of trackers on behavioural change.

--- Insert Table 5 about here ---

\section{Theme 3: Preferred and disliked features (Table 5)}

i. Preferred features. Step counting was most frequently mentioned by participants as the favoured feature.

This finding was connected to the above subtheme that participants were more aware of active time than sedentary time. In terms of prompts about SB, it appeared that vibration or buzzing was a more effective prompt than the coloured bar or beeps featured on some devices with all 9 participants using the Garmin Vivosmart and Jawbone Up24 having the buzzing feature agreed with this. Many (12 participants) liked getting real time feedback of their behaviour on the device or on the apps, although a few preferred using the web or computerbased feedback. The aesthetics of the trackers were considered to be crucial in determining preference and likelihood to use. Two women reported that they would not wear the tracker going out due to the way they looked. Some participants preferred trackers which had a smaller design (e.g., Fitbit One, Garmin Vivoactive, Jawbone Up 24) but also said that the small size would make trackers less likely to be noticed or harder to view 
and operate. The majority of participants liked the WATS that had a larger screen and clear text (Garmins and

A few participants were concerned about the accuracy of the devices, noting that some trackers had not accurately measured their activity. Some noted that the trackers appeared to display many more steps than their actual steps and didn't register light intensity PA (e.g., standing, slow walk) as a break from sitting. In addition, participants reported that the trackers were improperly validating activities other than walking, such as yoga or strength training, which further made participants feel unmotivated because their efforts were not properly recognised.

\section{Theme 4: Concerns related to cancer}

Most participants expressed their concerns that treatment side-effects such as tiredness, fatigue and losing weight limited their exercise efforts. Lymphedema is one of the most common side-effects after breast cancer treatment among those who have had lymph nodes removal surgery or radiation therapy and usually occurs in 
the arms and hands [20].Two participants expressed their concerns that lymphedema may cause discomfort

Some noticeable concerns participants brought up involved the potential adverse effect of these trackers on the treatment (radiation therapy), stimulation of cancer tissues and effect on physical health. Two BCS noted their concern about the potential adverse effects that WATs could have on their health.

\section{Theme 5: Strategies for application in breast cancer survivors}

Overall, participants' impressions of wearable activity trackers were positive. Participants generally enjoyed the opportunity to wear the trackers, and found them helpful in changing behaviours. People also expressed willingness to buy a tracker in future to monitor their PA/SB with the price of AUD 100-150 considered acceptable. When asked for their opinion on how to best utilise wearable activity trackers to promote PA among BCSs, participants suggested that peer support from other women with breast cancer might assist and complement the use of these devices. In addition, they would be comfortable to share their data with, and gain encouragement from, women in the same situation. Others thought that friends and social networks (Facebook, Twitter) could assist BCSs to increase their activity.

Some participants suggested the need for greater promotion of physical exercise from doctors and oncologists for women with breast cancer. It was noted that women were being measured and tested frequently during treatment so similar monitoring could be done with PA. One participant suggested her experience of joining an exercise competition held by her insurance company to win a fitness band could be a feasible strategy.

\section{Discussion}

Increasing physical activity is an important and well recognised strategy for improving health outcomes amongst BCS. WATs are rapidly growing as promising technology to promote such behaviours, in part due to their recognizable strengths in boosting motivation, physical ability and their psychological triggering effect 
[10,21-23]. However, there has been limited evidence about the usability and acceptability of such technology

amongst cancer survivors. To our knowledge, the present work, though exploratory, is the first in-depth study exploring factors associated with wearable technology acceptance and including suggestions of feasible strategies to apply such technologies amongst BCS.

We found that the majority of BCS experienced wearing the trackers as comfortable and helpful in motivating them to improve their PA levels and reduce SB. In the view of perceived usefulness of the wearable technology, BCS showed some similarities as well as significant differences with the general population [11,14,24,25,21]. Interestingly, we did not observe any consistent differences in WAT preferences between the active and inactive participants. The greatest advantage of wearable trackers is that they help users increase awareness of their current activity levels [11]. Previous studies showed that the perceived usefulness of the technology was usually evident when a user had a health concern [24]. Our study consolidated that evidence, in that participants perceived more awareness and motivation to increase exercise than women without the disease. However, participants mostly increased their awareness of the amount of time spent active or number of steps achieved, but not the time spent sedentary. Overall, there was little awareness of the importance of SB reduction in this BCS group. SBis a particularly important consideration among cancer survivors, as it is adversely associated with some mechanisms operative in carcinogenesis [26], and with increased overall cancer mortality regardless of moderate-to-vigorous activity levels [27,28]. Future interventions aiming at promoting healthy lifestyles for cancer survivors, including BCS, should simultaneously focus on double goals of increasing PA and reducing SB using promising technology support such as WATs.

Our study participants shared some of the same barriers to new technology acceptance with the general older population such as limited tech-knowledge (self-confidence), lack of readiness to conversion and not being interested in new technology [11,14,24]. The provision of additional technical support (possibly delivered faceto-face or easy-to-understand manual documents) might be beneficial in interventions targeting older adults, to allow them to make full use of the devices. One of the key lessons we learned from this study related to which specific features of wearable activity trackers were preferred by our BCS participants. Similar to the general older population, BCS liked the most simple features of the trackers: the clear and achievable step-goal display, instant feedback, and easy-to-read screen and text display [11]. Charge-free battery life is suggested as important feature especially for the older population. BCS also found the buzzing trigger more effective than the 
visual trigger as a sedentary prompt. Participants suggested that they like to receive frequent positive

Importantly, there were some specific disease-related barriers to use of the WATs noted. These included chronic comorbidities that sometimes made it difficult to wear the trackers, treatment side effects and fear of electromagnetic effects. The provision of advice on appropriate strategies to overcome treatment side effects may help to promote PA. There has been long-time concerns amongst the public in relation to electromagnetic radiation from wearable devices such as cell phone or activity trackers, despite there being little evidence to support such arguments [29]. Education materials may need to specifically address these concerns if wearable devices are to be incorporated into interventions in this population.

Peer support or involvement of doctors and oncologists in promoting PA were suggested as potentially feasible strategies to encourage WAT use among BCS. Peer support and health professionals' advice have been found feasible and effective in delivering behaviour change interventions among cancer survivors [31, 32]. Our BCS participants expressed they were encouraged to receive advice on PA and willing to share their exercise monitoring progress with their doctors and oncologists. They also felt motivated and encouraged to do exercise with women having the same medical conditions with them and using the same activity trackers. Furthermore, wearable technology can be connected with social networks, e.g., Facebook or Twitter, to deliver the peer support. Thus, there is a viable potential of pursuing these approaches in behavioural interventions applying wearable technology. 
This study has several considerable strengths. We provided participants with the WATs for a period long enough (two weeks per device) to give some insight into longer-term use of these devices rather than just the initial impressions. In addition, we tested a variety of commercially available devices with different features, which helped us gain more perceptions into particular features that are more acceptable and feasible for this population. The primary limitation of our study is that participants did not try all the testing devices (six fitness bands) and some trackers (the Garmin Vivofit2, Vivosmart and Fitbit) were tested more frequently than others (Jawbone,Polar A300 and Garmin Vivoactive) due to some technical issues that occurred during the trial (e.g., stop-syncing Jawbone and Polar A300, and broken screen Garmin Vivoactive). Hence, the overgeneralizing findings are more applicable for three models Garmin Vivofit2, Vivosmart and Fitbit One. Further, the mean age of participants in our study (59 years) is younger than post-menopausal BCS overall. This could have affected perceptions, particularly relating to ease of use and comfort with technology. While the data we collected were highly informative, more research is needed to better understand the optimal design of interventions using wearable technology for breast cancer survivors. It is also worth exploring the factors associated with adherence to long-term use of WATs in this group.

\section{Conclusion}

A crucial strength of WATs is in raising breast cancer survivors' awareness of their PA and SB levels. Our key finding is that activity trackers appear to be acceptable to this population and therefore may be a feasible and cost effective strategy to use in PA/SB interventions in this group. Effective wearable technology interventions may benefit from taking advantage of the simple features of the trackers (e.g., step counts and buzzing) paired with other behavioural change techniques, such as specialist counselling, doctor monitoring and peer support. Clear and simple instructions guiding installation of apps and use of the device could also be important for maximising uptake and maintenance. 


\section{References}

1. Crowgey T, Peters KB, Hornsby WE, Lane A, McSherry F, Herndon JE, West MJ, Williams CL, Jones LW (2013) Relationship between exercise behavior, cardiorespiratory fitness, and cognitive function in early breast cancer patients treated with doxorubicin-containing chemotherapy: a pilot study 1. Applied Physiology, Nutrition, and Metabolism 39 (6):724-729

2. Rock CL, Doyle C, Demark-Wahnefried W, Meyerhardt J, Courneya KS, Schwartz AL, Bandera EV, Hamilton KK, Grant B, McCullough M (2012) Nutrition and physical activity guidelines for cancer survivors. CA: a cancer journal for clinicians 62 (4):242-274

3. Cancer Council Australia Staying healthy after treatment.

http://www.cancercouncil.com.au/15308/b1000/living-well-after-cancer-45/living-well-after-cancerstaying-healthy-after-treatment/. Accessed 10/29/2016 2016

4. Harrison S, Hayes SC, Newman B (2009) Level of physical activity and characteristics associated with change following breast cancer diagnosis and treatment. Psycho-Oncology 18 (4):387-394

5. Demark-Wahnefried W, Aziz NM, Rowland JH, Pinto BM (2005) Riding the crest of the teachable moment: promoting long-term health after the diagnosis of cancer. Journal of Clinical Oncology 23 (24):5814-5830

6. Bluethmann SM, Vernon SW, Gabriel KP, Murphy CC, Bartholomew LK (2015) Taking the next step: a systematic review and meta-analysis of physical activity and behavior change interventions in recent post-treatment breast cancer survivors. Breast cancer research and treatment 149 (2):331-342 7. Dempsey PC, Owen N, Yates TE, Kingwell BA, Dunstan DW (2016) Sitting Less and Moving More: Improved Glycaemic Control for Type 2 Diabetes Prevention and Management. Current Diabetes Reports 16 (11):114

8. Pureprofile (2015) PRESS RELEASE: Wearables work - Australians more active with fitness trackers. PRESS RELEASE: Wearables work - Australians more active with fitness trackers. Accessed 15/12/2016

9. Michie S, Abraham C, Whittington C, McAteer J, Gupta S (2009) Effective techniques in healthy eating and physical activity interventions: a meta-regression. Health Psychology 28 (6):690 10. Cadmus-Bertram LA, Marcus BH, Patterson RE, Parker BA, Morey BL (2015) Randomized trial of a Fitbit-based physical activity intervention for women. American journal of preventive medicine 49 (3):414-418

11. Mercer K, Giangregorio L, Schneider E, Chilana P, Li M, Grindrod K (2016) Acceptance of commercially available wearable activity trackers among adults aged over 50 and with chronic illness: a mixed-methods evaluation. JMIR mHealth and uHealth 4 (1)

12. Shih PC, Han K, Poole ES, Rosson MB, Carroll JM (2015) Use and adoption challenges of wearable activity trackers. iConference 2015 Proceedings 
13. Evenson KR, Goto MM, Furberg RD (2015) Systematic review of the validity and reliability of consumer-wearable activity trackers. International Journal of Behavioral Nutrition and Physical Activity $12(1): 1$

14. McMahon SK, Lewis B, Oakes M, Guan W, Wyman JF, Rothman AJ (2016) Older Adults' Experiences Using a Commercially Available Monitor to Self-Track Their Physical Activity. JMIR mHealth and uHealth 4 (2)

15. El-Amrawy F, Nounou MI (2015) Are currently available wearable devices for activity tracking and heart rate monitoring accurate, precise, and medically beneficial? Healthcare informatics research $21(4): 315-320$

16. www.popsugar.com.au (2015) The Most Popular Fitness Trackers. Accessed 20/11 2016 17. Patton MQ (1990) Qualitative evaluation and research methods. SAGE Publications, inc, 18. Braun V, Clarke V (2006) Using thematic analysis in psychology. Qualitative research in psychology 3 (2):77-101

19. Ltd QIP (2012) NVivo qualitative data analysis software. QSR International Pty Ltd, 20. Norman SA, Localio AR, Potashnik SL, Torpey HAS, Kallan MJ, Weber AL, Miller LT, DeMichele A, Solin LJ (2009) Lymphedema in breast cancer survivors: incidence, degree, time course, treatment, and symptoms. Journal of Clinical Oncology 27 (3):390-397

21. Wang JB, Cadmus-Bertram LA, Natarajan L, White MM, Madanat H, Nichols JF, Ayala GX, Pierce JP (2015) Wearable sensor/device (Fitbit One) and SMS text-messaging prompts to increase physical activity in overweight and obese adults: A randomized controlled trial. Telemedicine and eHealth 21 (10):782-792

22. Thompson WG, Kuhle CL, Koepp GA, McCrady-Spitzer SK, Levine JA (2014) "Go4Life" exercise counseling, accelerometer feedback, and activity levels in older people. Archives of gerontology and geriatrics 58 (3):314-319

23. Washington WD, Banna KM, Gibson AL (2014) Preliminary efficacy of prize-based contingency management to increase activity levels in healthy adults. Journal of applied behavior analysis 47 (2):231-245

24. Kim S, Gajos KZ, Muller M, Grosz BJ (2016) Acceptance of Mobile Technology by Older Adults: A Preliminary Study.

25. O'Brien T, Troutman-Jordan M, Hathaway D, Armstrong S, Moore M (2015) Acceptability of wristband activity trackers among community dwelling older adults. Geriatric Nursing 36 (2):S21-S25 26. Lynch BM, Dunstan DW, Vallance JK, Owen N (2013) Don't take cancer sitting down. Cancer 119 (11):1928-1935

27. Matthews CE, George SM, Moore SC, Bowles HR, Blair A, Park Y, Troiano RP, Hollenbeck A, Schatzkin A (2012) Amount of time spent in sedentary behaviors and cause-specific mortality in US adults. The American journal of clinical nutrition 95 (2):437-445 
28. Campbell PT, Patel AV, Newton CC, Jacobs EJ, Gapstur SM (2013) Associations of recreational physical activity and leisure time spent sitting with colorectal cancer survival. Journal of Clinical Oncology:JCO. 2012.2045. 9735

29. National Cancer Institute (2016) Electromagnetic Fields and Cancer. Accessed 01/11/2016 2016 
Table 1. Specific features of wearable activity trackers selected for testing in the study

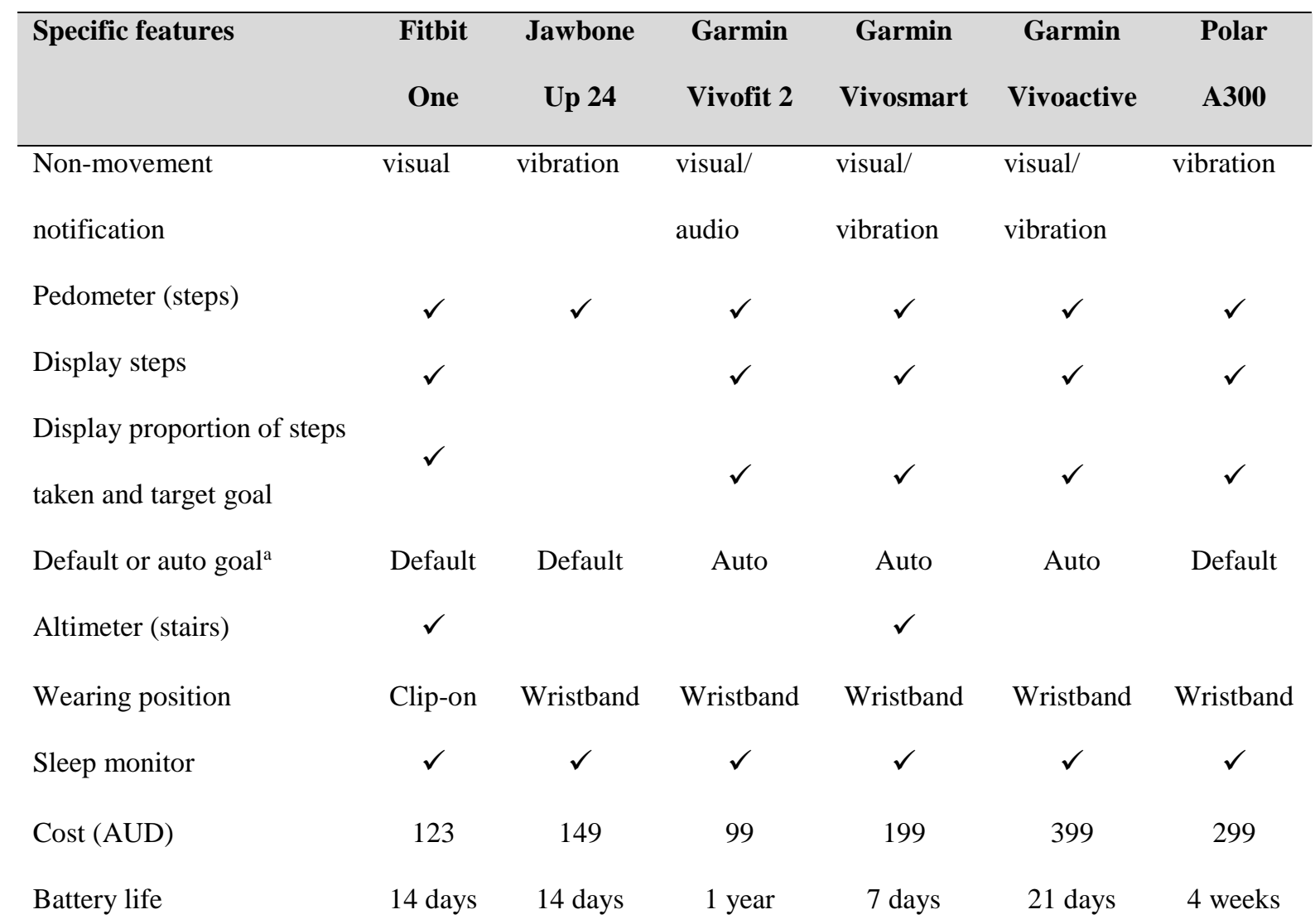

$\begin{aligned} & \text { Number of participants } \\ & \text { testing the device }\end{aligned}$
$\begin{aligned} & \text { a } \\ & \text { Default or auto-goal: "Default" indicates that devices have default step goals of } 10,000 \text { steps per day. "Auto }\end{aligned}$

a Default or auto-goal: "Default" indicates that devices have default step goals of 10,000 steps per day. "Auto goal" indicates that devices will create a daily step goal automatically based on user's previous activity levels, i.e, if user achieved only 5000 steps under the goal of 7,500 steps, the step goal will reduce to 6,500 steps on the next day to make the goal more achievable. 
Table 2. Focus group guide

\begin{tabular}{|c|c|c|}
\hline Topics & Questions & Elaboration questions \\
\hline $\begin{array}{l}\text { Awareness of } \\
\text { monitoring PA/ SB }\end{array}$ & $\begin{array}{l}\text { When you think of monitoring your } \\
\text { physical activity/sitting time, what comes } \\
\text { to mind? }\end{array}$ & $\begin{array}{l}\text { How does monitoring PA/sitting } \\
\text { time make you feel? Usefulness of } \\
\text { monitoring? Were you surprised of } \\
\text { how much you moved or sat? }\end{array}$ \\
\hline $\begin{array}{l}\text { Usefulness of the } \\
\text { wearable monitor }\end{array}$ & $\begin{array}{l}\text { When you wore your physical activity } \\
\text { monitor, how did you feel about wearing } \\
\text { it? }\end{array}$ & $\begin{array}{l}\text { Did you change your life routine? } \\
\text { What are more useful and less useful } \\
\text { sides of wearing the monitors? }\end{array}$ \\
\hline $\begin{array}{l}\text { Ease of use and } \\
\text { Preference of features }\end{array}$ & $\begin{array}{l}\text { How easy or difficult did you find using } \\
\text { the activity monitor? What are your likes or } \\
\text { dislikes about the activity monitor and/or } \\
\text { its app? }\end{array}$ & $\begin{array}{l}\text { If difficult, did you need help from } \\
\text { others in using this new technology? } \\
\text { Any suggestions to resolve } \\
\text { difficulties? Any preference } \\
\text { features? Any privacy concerns? }\end{array}$ \\
\hline $\begin{array}{l}\text { Strategies to apply } \\
\text { wearable technology in } \\
\text { future }\end{array}$ & $\begin{array}{l}\text { Your thoughts about the feasible } \\
\text { application of wearable technology to } \\
\text { improve physical activity and reduce } \\
\text { sedentary behaviour amongst breast cancer } \\
\text { survivors? }\end{array}$ & \\
\hline
\end{tabular}


Table 3. Participant characteristics ${ }^{a}$

\begin{tabular}{|c|c|c|c|c|c|c|c|c|}
\hline Participant & Age & $\begin{array}{l}\text { Breast cancer } \\
\text { stage }\end{array}$ & $\begin{array}{l}\text { Treatment } \\
\text { received }^{b}\end{array}$ & $\begin{array}{l}\text { Physical } \\
\text { activity level }\end{array}$ & $\begin{array}{l}\text { Technology } \\
\text { skill }\end{array}$ & 1 $^{\text {st }}$ tracker & $2^{\text {nd }}$ tracker & $3^{\text {rd }}$ tracker \\
\hline 1 & 57 & 3 & $\mathrm{SU}+\mathrm{CH}+\mathrm{HR}$ & Active & Intermediate & Vivofit2 & Vivosmart & Polar A300 \\
\hline 2 & 60 & 3 & $\mathrm{SU}+\mathrm{CH}$ & Inactive & Novice & Polar A300 & Vivofit2 & Vivoactive \\
\hline 3 & 62 & 2 & $\mathrm{SU}+\mathrm{CH}+\mathrm{RA}+\mathrm{HR}$ & Inactive & Intermediate & Fitbit One & Vivosmart & Vivofit2 \\
\hline 4 & 60 & 3 & $\mathrm{SU}+\mathrm{CH}+\mathrm{RA}$ & Active & Skilled & Vivosmart & Vivoactive & Fitbit One \\
\hline 5 & 62 & 3 & $\mathrm{SU}+\mathrm{CH}+\mathrm{RA}+\mathrm{HR}$ & Inactive & Novice & Vivosmart & Polar A300 & N/A \\
\hline 6 & 61 & 3 & $\mathrm{SU}+\mathrm{CH}+\mathrm{RA}+\mathrm{HR}$ & Active & Intermediate & Fitbit One & Vivoactive & N/A \\
\hline 7 & 62 & 3 & $\mathrm{SU}+\mathrm{CH}$ & Active & Novice & Vivofit 2 & Vivosmart & N/A \\
\hline 8 & 62 & 3 & $\mathrm{SU}+\mathrm{CH}+\mathrm{RA}+\mathrm{HR}$ & Inactive & Novice & Vivofit 2 & Polar A300 & N/A \\
\hline 9 & 51 & 2 & $\mathrm{SU}+\mathrm{CH}$ & Inactive & Intermediate & Fitbit One & Vivosmart & N/A \\
\hline 10 & 52 & 2 & $\mathrm{SU}+\mathrm{CH}+\mathrm{RA}+\mathrm{HR}$ & Inactive & Intermediate & Fitbit One & Vivofit 2 & N/A \\
\hline 11 & 64 & 2 & $\mathrm{SU}+\mathrm{CH}+\mathrm{RA}$ & Active & Novice & Vivofit 2 & Fitbit One & N/A \\
\hline 12 & 57 & 2 & $\mathrm{SU}+\mathrm{CH}$ & Active & Intermediate & Vivosmart & Vivofit 2 & N/A \\
\hline 13 & 56 & 2 & $\mathrm{SU}+\mathrm{CH}+\mathrm{RA}+\mathrm{HR}$ & Inactive & Intermediate & Vivofit 2 & Vivosmart & N/A \\
\hline 14 & 57 & 2 & $\mathrm{SU}+\mathrm{CH}+\mathrm{RA}$ & Active & Skilled & Jawbone Up 24 & Vivofit 2 & N/A \\
\hline
\end{tabular}


Theme 1: Trackers increased self-awareness and motivation of $\mathrm{PA} / \mathrm{SB}$

I could say before I started I felt that I wasn't doing enough activity, so going into it I was keen to see what does my everyday activity measure and I was sort of quite surprised at how much I actually did. I walked to the station and this [the tracker] said "Oh, it's 1500 steps" so it did change my thinking a bit on that plane.

Definitely you didn't realise how long you [have been sitting], I think I've been sitting for 15 minutes and it's [actually] an hour, particularly when you're working, time just flies past and all of a sudden.... And I also didn't realise that you should move as often as they say that you should, but yes definitely time goes fast.

If you get to say 8,000 [steps] in a day, you're more motivated to do those extra 2,000 because you're so close. It's like "Why would I stop now?" I might as well keep going.

What was good was I realised that if I left the car and went somewhere I would get enough steps. It really didn't matter how far it was if there was some purpose, then I would get a lot more steps. And I went to a dog walks, went with a friend to walk. I didn't realise it was quite easy to hit the target given that. I had to do that because I wouldn't have time to run around getting steps, so it [the exercise] had to fit in.

When I first started wearing it [the tracker] I did quite consciously go on some walks and things that I know I would never have before, so I thought that was quite good, but it actually wore off after a while. I think you need something to encourage you to do it [exercise].

I think women with breast cancer would be so much more motivated. I mean if you're just trying to lose five kilos, well, maybe you're motivated. But if you want to stop cancer from coming back and you can contribute to it in some way, to me that was a massive for me to get up and start walking.

Theme 2: BCS confidence and comfort with wearable technology
Once I understood how it worked, it was easy, you know you hit sync on this, open the app and little whirly twirly things happened and it spat out the findings so

I had no trouble using them [the trackers] [...]all I had to put in my steps, at work we're doing a stepathon, the 10,000 steps, that was easy. You go to the calendar and it was easy just to fill in.

It [Garmin vivofit] was very simple, I set the steps to come up first as I was wearing the watch on the other hand but that changed [my physical activity] and it was simple. I didn't have any issues with the charging.

It's not simple, I agree. It took a few days for me to get used to widgets and apps and things like that but they are [the instruction] quite limited so that took a little bit to set up.

I have a little bit of trouble with the Garmin's getting them to set up, so in the end I just gave up.

I am a bit old school I don't think the experience [using the tracker] would make me necessarily go out and buy one. If I felt I was reasonably active doing what I do, in my normal daily activities, I would probably be happy with that, but then I tend to ignore technology if I can.

Using the app I just feel as if I had very limited [skills] ... and it's probably through my lack of skills... and limited interaction with it. Like, I knew how to sync it and look at the stuff and read it and say "That was quite interesting" but I didn't do anything else with it [the app].
P3, FG1, Age 62

P5, FG2, Age 62

P10, FG3, Age 52

P4, FG1, Age 60

P2, FG1, Age 60

P14, FG4, Age 57

P5, FG2, Age 62

P9, FG3, Age 51

P4, FG1, Age 60

P4, FG1, Age 60

P2, FG1, Age 60

P7, FG2, Age 62

P7, FG2, Age 62 
Theme 3: Preferred and disliked features of activity trackers

\section{i. Preferred features}

ii. Disliked features

Theme 4: Concerns related to the disease
I just followed the step count. I found the step count encouraged me to have to get over my 10,000 steps. [...] I think, because that's a number that just always sticks in my head.

I thought it [the buzzing] was a good, the ones [trackers] that either buzzed at you, that I noticed. The first one I had didn't have any signs so it didn't make any difference but the ones that buzzed at me I consciously thought "Yeah, I've been sitting for long time".

I had the Polar first [...] I thought it was quite heavy and quite clunky but then I had the two Garmins and in the end I decided that was my favourite even though it was heavier. I thought it was easier to push the buttons and see where you were rather than the others.

If I buy one I would buy just for the fact it's got a bigger screen, easier to see, the numbers are facing you rather than sideways. You can actually sit there and actually look at it [...] without having to swipe through that, you can either go into it or ignore it or you can set it up a little more personalised.

It was a Garmin, say the goal is 10,000 [steps] and you had a lazy morning, it drops down to 8,000 and then 6,000 and [... "No, I still want to do my 10,000" [...] I would rather have the goal set and if I didn't reach my goal, that's something I am going to have to deal with but with the goal changing, I could have sat there and the goal would have just dropped, it didn't seem to be rationale.

I looked down, it [the tracker] had a message that said "Move!". I thought, that's a bit cheap because I've been busy all day working and busy all day, and now I'm finally sitting down and it wants me to move again.

I did [ignored the buzzing], by the end of the six weeks I couldn't be bothered [by the buzzing].

For example strength training, like a pump class, there's no category that says strength training, like sometimes you would use walking [to measure strength training], I would get my steps around the gym, which are a lot but that [number of steps collected] is kind of nothing.

Also, lymphedema, taking the nodes off, I can't have that pressure on that side [of the arm] so that's another thing.

Because I'm on medication, and I've got the joint issues. So that's really, I'm really- not struggling but just it stops me doing, you know 5,000 I'm all right, if you push me to 6 or 7 [thousand steps], I'm in tears because of the joints.

The chemo killed my brain. Also, weight loss, because I put on a lot of weight with the steroids, etc. as well, which in turn means I don't feel like walking or exercising because I feel so tired all the time.

I found my breast surgeon and the oncologist didn't say anything about exercise. It's really just up to me. My breast surgeon said "Just go back to your normal life" is what he said.

I don't want something that's electronic on my body because it might influence another episode, I don't know, you just don't know.

I didn't like wearing it at night. I didn't feel comfortable. I wanted to be away from all sort of electrical kinds of things when I sleep. I even have the clock radio quite away and I don't sleep near any power points or anything. I've had breast cancer a few times, it's always been caught early but you still
P9, FG3, Age 51

P1, FG1, Age 57

P2, FG1, Age 60

P5, FG2, Age 62

P1, FG1, Age 57

P11, FG3, Age 64

P2, FG1, Age 60

P4, FG1, Age 60

P9, FG3, Age 52

P13, FG4, Age 56

P8, FG3, Age 62

P11, FG3, Age 64

P10, FG3, Age 52

P11, FG3, Age 64 
think you do what you can to keep away from any kind of an influence you think might be affecting you.

Theme 5: Possible strategies for Wearable technology application
I think if you offered it to a group of women who were going through treatment, whether it's their chemo or they had just finished and they were a group of women you had just got together and said "Why don't we all try using a device and build up our steps or monitor each other" I think that would be really positive. [...] I think a group of women like that it could be quite encouraging.

In this day of social media I have a lot of groups of friends that are Fitbit people and they have their own groups and there is a bit of competition amongst the friends and not that it's a "You must do this", "Who made 8,000 today", "Who made 9,000 today" and they give each other badges and pats on the back and so it becomes quite social and that's quite important I think. We always say if you train with a friend you're less likely to pull out but if you going to say "I am going to do it on my own" then it is easier.

They [the doctors] haven't said much but I think they should encourage people to do more exercise, really, not just go back to your normal life. "How much exercise are you doing? Are you able to monitor it?" This is what the surgeon could suggest getting one of those Fitbit, find out exactly how much you're doing and then exercise is really good so try and do more, try and have some goals. I think that should be encouraging people because it's good to get encouragement.
P2, FG1, Age 60

P6, FG2, Age 61

P11, FG3, Age 64

$P$ Paticipant, $F G$ Focus group 
Table 5. Positive and negative statements about the study activity trackers

\begin{tabular}{|c|c|c|}
\hline Tracker name & Positive statements & Negative statements \\
\hline Fitbit One & $\begin{array}{l}\text { "Fitbit would send you the encouraging emails } \\
\text { about your progress, that was good" }\end{array}$ & $\begin{array}{l}\text { "Fitbit was so unobtrusive, it was small, } \\
\text { could be out of sight and completely } \\
\text { unaware of" }\end{array}$ \\
\hline $\begin{array}{l}\text { Jawbone Up } \\
24\end{array}$ & $\begin{array}{l}\text { "Jawbone vibrates to remind you which is } \\
\text { good" }\end{array}$ & $\begin{array}{l}\text { "Sometimes I had no idea why it was } \\
\text { vibrating. Sometimes while I was walking, } \\
\text { sometimes it was } 10 \text { o'clock at night." }\end{array}$ \\
\hline $\begin{array}{l}\text { Garmin } \\
\text { Vivofit2 }\end{array}$ & $\begin{array}{l}\text { "You don't have to charge, has a long battery } \\
\text { in it. I loved that because sometimes when } \\
\text { you charge them and you forget about them" }\end{array}$ & $\begin{array}{l}\text { "It [Vivofit2] was clunky pressing the } \\
\text { button, you had to go through everything } \\
\text { and if you missed you would have to go } \\
\text { through. It was a bit annoying." }\end{array}$ \\
\hline $\begin{array}{l}\text { Garmin } \\
\text { Vivosmart }\end{array}$ & $\begin{array}{l}\text { "It was light, simple and was quite easy to } \\
\text { look at the steps and the goals" }\end{array}$ & $\begin{array}{l}\text { "Vivosmart was a bit annoying having to } \\
\text { clip it into [...] The sleep was interesting } \\
\text { but of the long-term it kind of didn't seem } \\
\text { to tell me anything" }\end{array}$ \\
\hline $\begin{array}{l}\text { Garmin } \\
\text { Vivoactive }\end{array}$ & $\begin{array}{l}\text { "You would be tapping away and swipe and } \\
\text { because it had a bigger screen like a picture } \\
\text { before you.[...] And it had a hell of a lot of } \\
\text { functionality." }\end{array}$ & $\begin{array}{l}\text { "I was critical of the Vivoactive because of } \\
\text { the chunkiness, it was clunky". }\end{array}$ \\
\hline Polar A300 & $\begin{array}{l}\text { "I like the way the Polar gave you points and } \\
\text { told you how much, half an hour more of } \\
\text { walking or } 3 \text { hours of up time that you needed } \\
\text { to do to get your points" }\end{array}$ & $\begin{array}{l}\text { "I didn't like the Polar at all, because it } \\
\text { was big and clunky and heavy so I just } \\
\text { stopped wearing it." }\end{array}$ \\
\hline
\end{tabular}

